\title{
Validation of Numerically Simulated Rapid-prototype Model by Photoelastic Coating
}

\author{
Peter Ficzere ${ }^{1 *}$, Lajos Borbas², Adam Torok ${ }^{3}$ \\ 'PhD student; MSc in Mechanical Engineering; assistant professor; Department of Vehicle Elements and Vehicle-Structure Analysis; Budapest \\ University of Technology and Economics; $H$-1111 Budapest, Stoczek u. 2. \\ ${ }^{2}$ PhD in Mechanical Sciences (Leonardo awarded in Material Science); MSc in Mechanical Engineering; associate professor Department of \\ Vehicle Elements and Vehicle-Structure Analysis; Budapest University of Technology and Economics; H-1111 Budapest, Stoczek u. 2. \\ ${ }^{3}$ PhD in Transport Sciences; MSc in Transport Sciences; MSc in Transport Management; researcher; Department of Transport Technology and \\ Economics; Budapest University of Technology and Economics; H-1111 Budapest, Stoczek u. 2.
}

\section{KEY WORDS}

Rapid Prototype, Finite Element Analysis, Orthotrop material law, Photoelastic coating, Experimental mechanics, Validation, Stress.

\begin{abstract}
The role of prototypes has increased considerably, especially functional prototypes, with the help of which the parts can be examined under the working conditions. Recently has been realised that the demand for functional prototypes and the use of built-in rapid prototypes in small series production and medical science have increased significantly. It became necessary to be able to decide whether the certain model can be used in its real load conditions in its application network. In more complicated cases even finite element analysis is need to be carried out. For the correct results at numerical simulation - assuming the exact knowledge of the loads and boundary conditions -the validated material properties also need to be known. The optical photostress method is a good method to validate the previously determined material properties.
\end{abstract}

\section{Introduction}

Rapid prototyping is an approach which allows crucial design decisions as early as possible. On the basis of all these it is obvious that the role of prototypes has increased considerably, especially that of the functional prototypes, with the help of which the parts can be examined under the later working conditions and furthermore real workload analysis can be done [1]. It is important to mention in some cases - for example - at medical applications before the use we would like whether the parts can be work under real loads in real working conditions. To answer these question a good opportunity the finite element analysis. But the answer is depends on the boundary conditions, and material law. To ensure they're appropriates we need to prove its with experimental. On the one hand the measurements, tests are for verifying our calculations, on the other hand they provide many data to designers and and to the operators. The measurements provide the basic data about the applied structural materials to define the characteristics of limit states in statical and time-varying load conditions. It can be determined only from measurements of a given structure, the characteristics of real workloads and the actual behavior of the structure is given. 
As a general principle: in order to reduce the probability of failure, the necessary measurements and tests - having regard to minimize production costs - should be made at the earliest possible stage of the design and manufacturing.

The calculation carried out with reasonable care (modeling) procedures over and above in accordance with the chosen measuring techniques by using complementary (hybrid method) may be determined on the exact stress components of the parts and the structures, emerging in strains and stress distributions under load.

There is no possibilities directly measure the stresses in a structure as a result of external loads. These are have to be defined in an indirect way. Namely with the help of the deformation of the loaded structures. In general case the deformation changes point by point on a structure. Three quantity is needed to describe the status of plane stress in a given point. These are the normal stress components $\left(\sigma_{x}, \sigma_{y}\right)$, as well as the shear stress component $\left(\tau_{x y}\right)$. Fig 1 is shown the location of the principal stresses in general case [2].

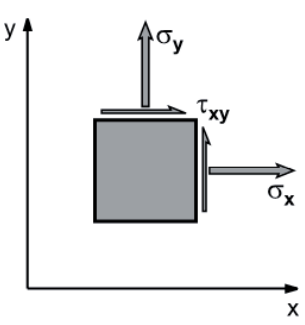

a

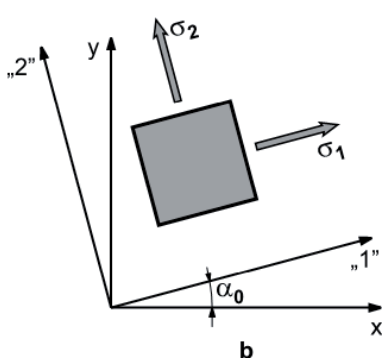

b

Fig. 1: Plane stress state (a) stress components in an arbitrary point (b) principal stresses and their positions [3].

Fig 2 illustrates deformations caused by the presented stresses.
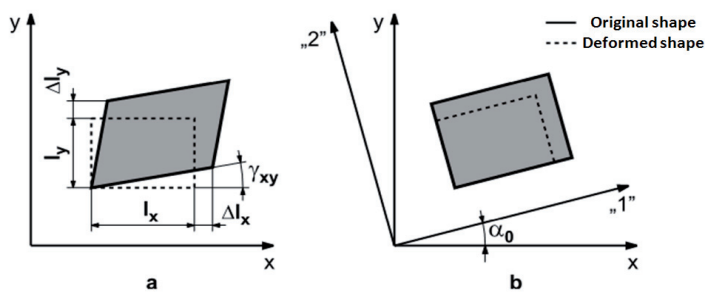

Fig. 2: Deformation of a surface point (a) in general position (b) in the direction of principal strains [3]

In the case of sufficiently small-length sides $\left(l_{x}, l_{y}\right)$ and homogeneous stress state the following rela- tion is true:

$\varepsilon x=\frac{\Delta l_{x}}{l_{x}}$,és $\varepsilon y=\frac{\Delta l_{y}}{l_{y}}$

As it is shown in Fig 2 by an appropriate rate of turning of the distorted elements we can find any plane element segment, where is not distorsion. The stress and strain components that are related to this rotated angle are called to principal stress and principal strain components. In linear elastic case to determine these principal strain componenents the Hooke-law can helps us. The values of the principal strain componenents are (2) - (3):

$$
\begin{aligned}
& \varepsilon_{1}=\frac{\varepsilon_{x}-\varepsilon_{y}}{2}+\frac{1}{2} \sqrt{\left(\varepsilon_{x}-\varepsilon_{y}\right)^{2}+\gamma_{x y}^{2}} \\
& \varepsilon_{2}=\frac{\varepsilon_{x}+\varepsilon_{y}}{2}-\frac{1}{2} \sqrt{\left(\varepsilon_{x}-\varepsilon_{y}\right)^{2}+\gamma_{x y}^{2}}
\end{aligned}
$$

To determine the principal planes direction $\varphi$ (4):

$\tan 2 \varphi=\frac{\gamma_{x y}}{\varepsilon_{x}-\varepsilon_{y}}$

If an isotropic material property is assumed then - knowing the material properties - from the components of strains the stress components can be easily calculated as follows (5) - (7):

$$
\begin{aligned}
& \sigma_{x}=\frac{E}{1-\nu^{2}}\left(\varepsilon_{x}+\nu \varepsilon_{y}\right) \\
& \sigma_{y}=\frac{E}{1-\nu^{2}}\left(\varepsilon_{y}+\nu \varepsilon_{x}\right) \\
& \tau_{x y}=G \gamma_{x y}
\end{aligned}
$$

where: $\mathrm{E}[\mathrm{MPa}], \mathrm{G}[\mathrm{MPa}]$ are the elastic and the shear modululus, $v$ is the Poisson-ratio [-]. Similarly to the principal strains the principal stress components can be determined, but in this case the (x.y) lower indices is replaced by the principal directions $(1,2)$, as the same analogy.

If strain measurement was carried out in small area then it will not surely provide sufficient information with regards to the whole surface area. Extrapolation is not possible. Nowadays for whole surface investigation optical strain test procedures are used. These procedures makes visible the 
strains on the surface and therefore stresses can be calculated.

\subsection{Optical strain investigation}

The basic idea behind the methodology is the following: in an optically transparent material the stresses will cause birefringence. The difference in optical property is linear to the stress that has been caused. In this case a single ray of unpolarized light entering an anisotropic medium is split into two rays, each traveling in a different direction. One ray (called the extraordinary ray) is bent, or refracted, at an angle as it travels through the medium; the other ray (called the ordinary ray) passes through the medium unchanged. This phenomena can be investigated as interference between polarised filter. Photostress management is done by an optically active coating on the real surface. The resulted principal directions of birefringence is equal to the principal direction of stress state. The measurement results show immediately the real stress-state, stress distribution under real loading conditions.

Due to the changes of refracting index, the differenc in lightwave phases emitted by the loaded body is proportinal to the differences between components of principal stresses. This can be described by the optic-stress law (in linear range) (8):

$\sigma_{1}-\sigma_{2}=\frac{S}{v} m$

where: $\sigma_{1}$ and $\sigma_{2}$ are principal stress component [MPa], S photostress factor [-], dependent of light source wavelength, methodological characteristics), $v$ thickness of investigation layer [mm], $m$ difference in double refraction, called fringe pattern.

The shown optical picture describes the average of changes in birefringence along to $v$ thickness. $\mathrm{S}$ can be laboratically determiend - by the usage of similar light condition as in the analysis - in a special equipment with known load pattern, and calibration.

The test procedure can be defined in two main areas:

\section{- Modeling (or transmission) process, \\ - Layer coating (or reflectance) method.}

In the first case stress optical image is prepared by illuminating the prepared modell with corresponding optical polarization properties in a load frame. In the second case a coating substrated is used with corresponding optical polarization characteristics in order to (with actual installation conditions) give the necessary load to receive the optical polarization reflection image.

On Fig 3. the optical stress analysis can be investigated.

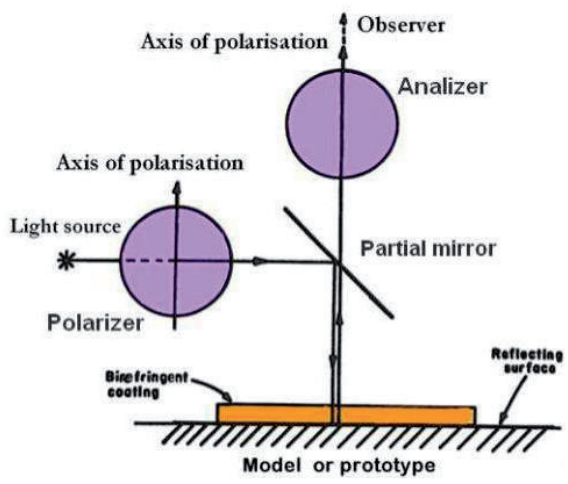

Fig. 3: Method of optical stress analysis [3].

Between polarizing filters the illuminated loaded model (the coating layer) shows two fringes. Namely one is referring to the magnitude of the principal stresses (proportional to the birefringence change). This is called to isochromatic fringe. As well as the fringes shows the isoclinic fringes, which show the directions of the principal stresses. If we record the fringes in different polarizer settings then we can draw up them into one figure. This drawn up network called to trajectory. Color bars converting to stress by calibration. The properties of the investigated optically active layer can be defined by compared the calculated and measured results of the stress state a simple geometry which has characteristics known loaded a pure stress (for example bending a fixed beam in the case of photoelastic coating layered method).

\subsection{The subject of the investigation}

In this case an assembled valve-housing (Fig. 4) will be presented to compare the results of an optical photostress and a finite element analysis.

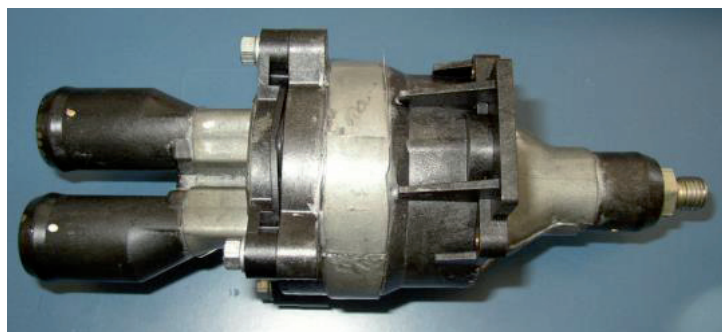

Fig. 4: The investigated assembled valve, (source: own photo). 
Fig. 5 shows the complexity and the difficulty of the model:

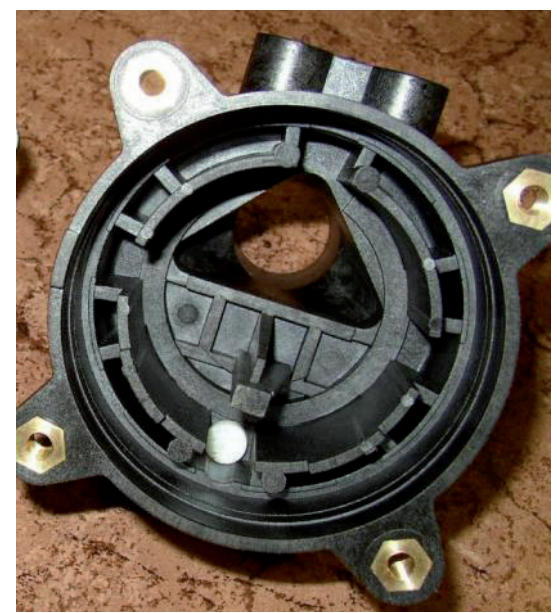

Fig. 5: One of the investigated valve-housing, (source: own photo).

The purpose of the investigation the detection of the emerging strain and stress condition on the surface in case of static load (internal pressure).

\subsection{Metrological characteristics of the coating layer}

For the test we have developed and used a coating layer which commonly used for the measurement of plastic polymer composites (Elastic modulus is elected to the given task with an appropriate sensitivity setting). The sensitivity index of the applied coating test layer had values $k=920 \mu \mathrm{S}$ (namely $0,92 \cdot 10^{-3} \mathrm{~mm} / \mathrm{mm}$ ) based on the calibration of test material layer in the case of layer thickness $d=1,7 \mathrm{~mm}$. According to the basic relationship of the optical photostress method, the detected specific elongation is:

$\varepsilon_{1}-\varepsilon_{2}=m \cdot k$

where: $m$ is the detected value of the fringe order of the color bar at the investigated point, $\varepsilon_{1}-\varepsilon_{2}$ is the difference of principal strains of the investigated surface points.

To convert the results of strain measurments to stresses, we used the investigated valve-housing material where Elastic modulus $E=1,25 \cdot 104 \mathrm{MPa}$ and as Poisson-ratio $v=0,42,[6]$, so in our case the following relationship is valid to the unit fringe order (case $m=1$ ):

$$
\sigma=\sigma_{1}=\frac{k \cdot E}{1+\nu}=\frac{0,92 \cdot 10^{-3} \cdot 1,25 \cdot 10^{4}}{1+0,42}=(11)
$$$$
=8,1 \mathrm{MPa}
$$

The relation between the principal strains ( $\varepsilon_{1}$ and $\left.\varepsilon_{2}\right)$ and the difference of the principal stresses ( $\sigma_{1}$ and $\sigma_{2}$ ) can be determined with the help of the (12).

$\sigma_{1}-\sigma_{2}=\frac{E}{1+\nu}\left(\varepsilon_{1}-\varepsilon_{2}\right)=m \frac{k E}{1+\nu}$

where: $E$ is the elastic modulus of the material of the investigated surface, $u$ its Poisson's ratio.

Valve-housig covers coated by test layer are shown in Fig. 6.

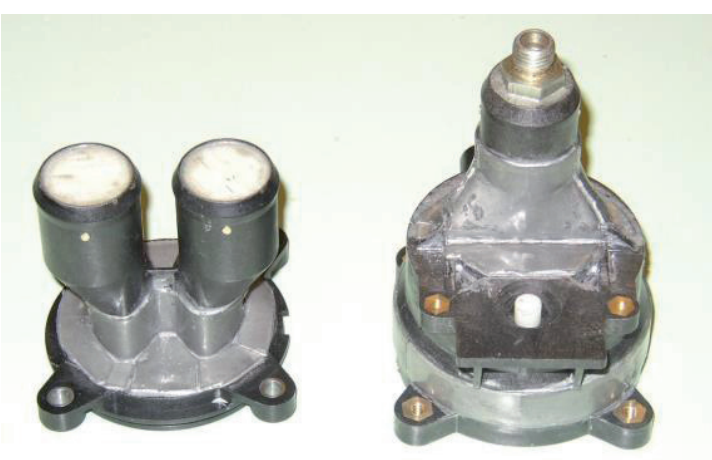

Fig. 6: Photo about of the glued-on coating test layer, (source: own photo).

\section{Methodology}

Fig 7 and 8 show the the measured evaluating scale during calibration on a fixed bended beam with the visible color pattern on the surface:

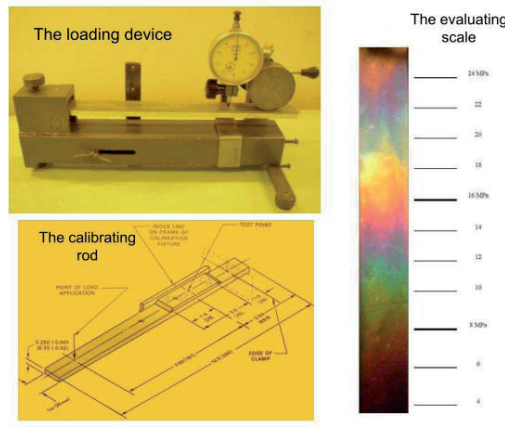

Fig. 7: The coating sensitivity determined by calibration [3].

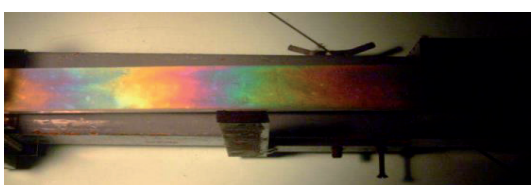

Fig. 8: The calibration beam in the loading device (subjected to bending) [3]. 
At the optical photostress coating layer method (Fig 3.) gives possibility to investigate the working structure under real loads with the analysis of the optical photostress image which appears on the coating test layer. This photoelastic coating test layer is glued directly to the working structures. In this case measured in the surface layer the relationship between the principal strains and principal stresses is given by the following formula (9):

$\sigma_{1}-\sigma_{2}=\frac{E}{1+\nu}\left(\varepsilon_{1}-\varepsilon_{2}\right)=m \frac{k E}{1+\nu}$

where: $\sigma_{1}[\mathrm{MPa}]$, and $\sigma_{2}[\mathrm{MPa}]$ are the principal stresses, $\varepsilon_{1}$ and $\varepsilon_{2}$ are the principal strains, $E$ is the elastic or Young modulus [GPa] of the investigated part, $v$ its Poisson-ratio [-], while $k$ is the sensitivity index of the applied coating layer (it takes into account the metrological characteristics of the coating layer, the wavelength of the illuminating light source as well as the thickness of the coating layer) $[-]$.

By applying the evaluation of received images of optical photostress method it is possible to determine the strain and stress state of the investigated part. In this case on the model (or on the part) along the choosen section starting from the unload areas by a steb by step numerical integration procedure we can determine the actual values of the stress components. Rapid evaluation of the fringe orders of the different optical photostress procedures character of the stress distribution, determination of the magnitude of the resulting strtess state can help effectively the designers work. Measured fringe orders on the loaded model or on the real structure provide an opportunity to immediately similarly to the finite element method - assess the stress distribution on the structure, to help isolate the critical places. A lightened beams loaded by three-point bending results fringe order distribution can be seen on the Fig. 9:

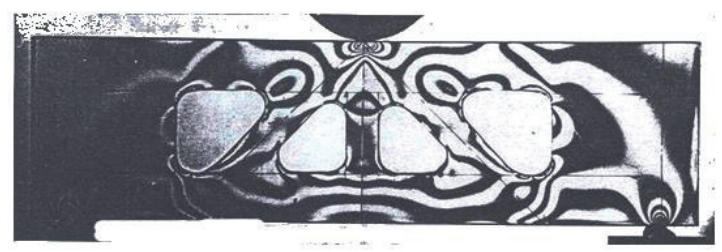

Fig. 9: Fringe pattern of a lightened three-point bended beam [3].
Based on the available fringe orders the stress distribution can also be easily determined by (9) see Fig. 10.

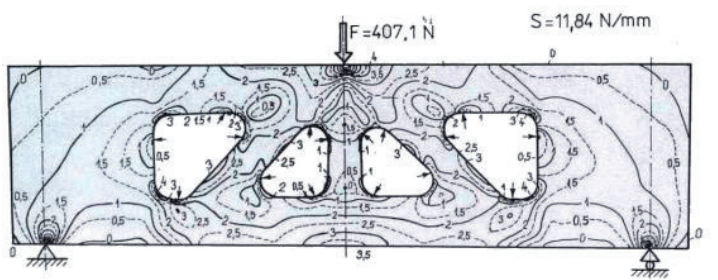

Fig. 10: Drawn up fringe order distribution of a lightened threepoint bended beam [3].

The optical photostress method over on the discovering the stress distribution of the investigated structures provides an opportunity for checking, monitoring the structures continously under real loads in working conditions, thus, the formation of failures can be detected in time. This type of the application of the measurement method in particular, consideration should be given to the prototyping, when the changes to be implemented on a structure has not a significant cost implications. Usually we used two-component resins (for example Epoxi, Polyester) for optical photostress method for modelling or for investigation coating layer. Most important requirements for test materials are the appropriate sensitivity (optical activity, namely high birefringence factor under load), shrinkagefree behavior (must not contain solvents), and low tendency to creep.

\subsection{Finite element analysis (FEA)}

Realising that the demand for functional prototypes and the use of built-in rapid prototypes in small series production and medical science have increased significantly, it became necessary to be able to decide whether the certain model can be used in its real load conditions in its application network. In more complicated cases we have to use finite element analysis to carry out this. For the finite element analysis a 3D CAD model is needed and the constraints, the loads and moreover the material properties are need to be known, as it has been shown in case of a linearly elastic model, means that the Elastic modulus and the Poisson ratio is necessary [4]. To evaluate the non-linear and time dependent behaviour further material properties is need to be specified. It is important to mention that in the case of a model with unknown material properties the results have to be verified 
by experiments carried out on real models [5].

In the case of rapid prototyping significantly more complex task to define the material properties - since their behavior is described exactly by the orthotrop model - therefore even more important to validate the material law what are determined based on the measurements. In this paper we will present an examination of the application of the optical photostress investigation as a method for validation. If new material parts are applied, usually even before the installation it is needed to determine whether the part can be loaded at his place in working conditions. Nowadays in the early stage of planning we can make strength test on arbitrarily complex parts as well. To do this, now generally the finite element analysis software and the additional 3D models are available and we know the investigated part's installation environment (constraints). The problem is usually in relation to the definition of the real loads that might occur and the appropriate description of the material law About the nature and the rate of the deformations, and the stress distribution by a given load, we can verifying the most with a coating layered optical photostress analysis.

\subsection{Description of the measurement}

In our study constant pressure increment of 0.5 bar load increments were examined the evolution of surface elongation-conditions of the plastic valve-housung. The pressure was increased with a manual hydraulic pump. First is above 4 bar slightly, then about 6 bar reached the pressure loss of the structure has become intense what is to say more and more pronounced reduction in hermetically sealed. Based on this reason why above 7 bar it was difficult to maintain the set pressure and to make recordings reliable (related pressure-stress distribution)

The loss of pressure was due to humpbacked deformation of the double-barrelled valve-housing that is, the seal - located between the two parties - was unable to perform its function in the case of values above 6 bar overpressure.

Failure of the structure is - as we shall see later a high degree of deformation of the valve-housig caused by the seal protrusion of the gasket nest.

\subsection{Finite element model}

For finite element analysis need to the 3D models of the valve-housings, need to know the material properties $(E, v)$ and loads over and above the contact factors arising from the assembly. As shown in the figure below 3D models can be observed well each housing halves complicated and complex geometric shaping (Fig.11).
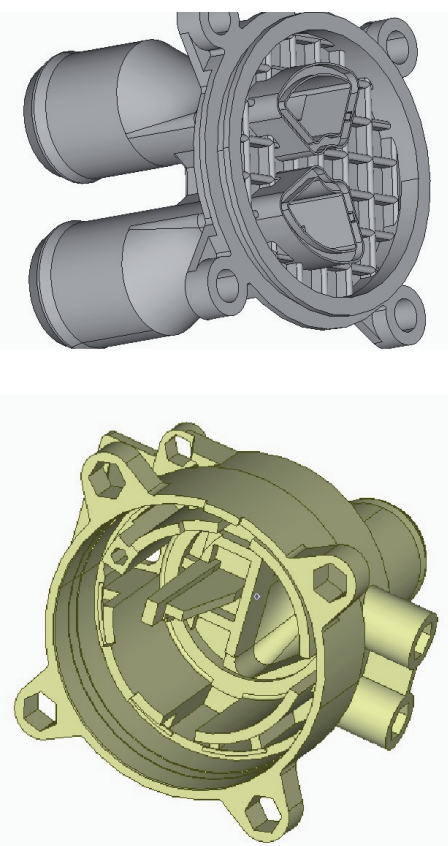

Fig. 11: 3D models of the investigated parts, (source: own edition).

The following figure (Fig. 12) as shown in the models is assembled.

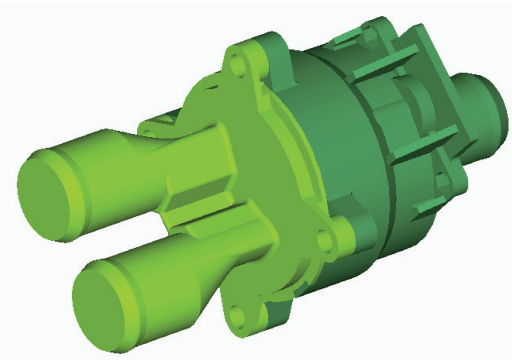

Fig. 12: Assembled valve-housings, (source: own edition).

The installation (Fig. 12) has not applied the bolt connections, on the other hand their effect on its place we deputized by a given clamping force load (bolt preload value). With this method we could save computing time and computational capacity demand. At the contact of the parts we defined the friction as a value of $\mu=0.1$. As load we have defined a 6 bar internal pressure onto the whole inner wall of the valve housings. This value was the reason of the failure in the real loadcase. In the next 
step we divided the investigated geometry to elementary sections (4 nodes tetrahedra), to get the finite element mesh (Fig. 13).

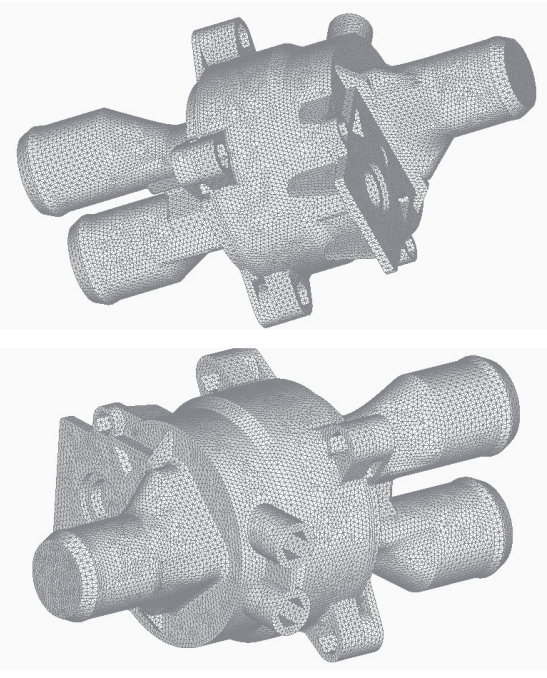

Fig. 13: Meshed geometries (source: own edition).

This mesh resulting 219212 elements. This was a static analyse. We used for the analysing the NX Nastran Solver.

\section{Results}

\subsection{The results of the optical photostress analysis}

Only those results are presented, which are found to be significant during the failure. As has already been mentioned, above 4 bar slightly, then about 6 bar reached the pressure loss of the structure has become intense what is to say more and more pronounced reduction in hermetically sealed. Based on this reason why above 7 bar it was difficult to maintain the set pressure and to make recordings reliable (related pressure-stress distribution)

The loss of pressure was due to humpbacked deformation of the double-barrelled valve-housing that is, the seal - located between the two parties - was unable to perform its function in the case of values above 6 bar overpressure.

Failure of the structure is - as we shall see later a high degree of deformation of the valve-housig caused by the seal protrusion of the gasket nest. On this basis essentially, we examined the deformation and stress distribution which are belong to the pressure 6 bar. The distribution of the fringe pattern belongs to the value of this can be seen on the Fig 14.

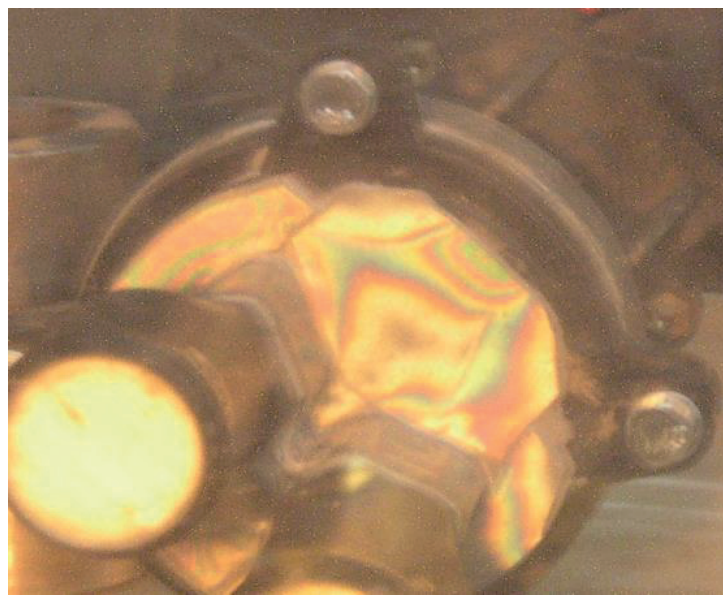

Fig. 14: The developing distribution of the fringe patterns on the critical surface, (source: own photo).

As shown in Fig. 14 the distribution of the fringe pattern was extremely spectacular, however, this can be even more important to immediately retrieve the so-called be drawn fringe pattern distribution figure (Fig. 15).

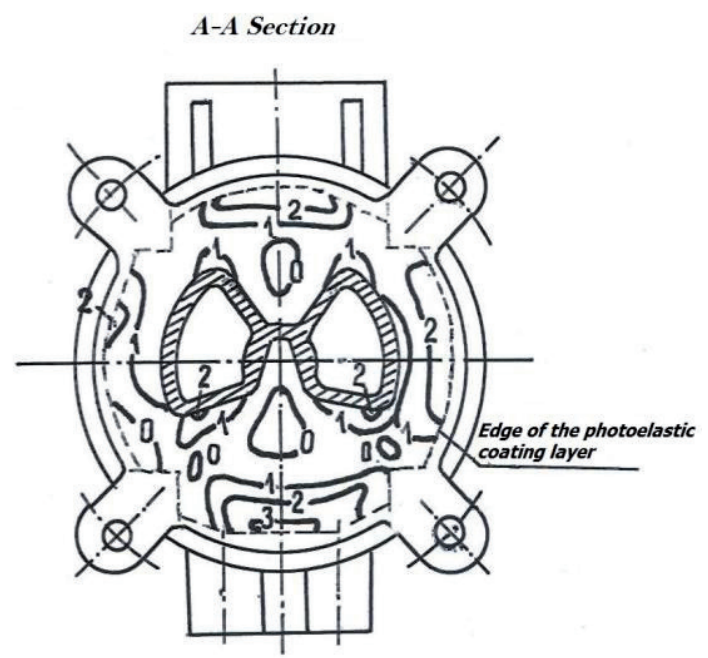

Fig. 15: The be drawn fringe pattern distribution on the investigated surface (source: own edition).

As shown well in Fig. 15 from the be drawn fringe pattern the emerged distribution on the given surface. The direction of stress growth can easily be determined, as well as clearly identifiable the unloaded (surrounded by $m=0$ line of fringe pattern) areas. Using the (11) relationship the stresses can also be rated. For each value of the fringe pattern must be assigned numeric values corresponding to stress values. On the fringe pattern in the case 
of $\mathrm{m}=1$ belongs to $8.1 \mathrm{MPa}$ stress, in the case of $m=2$ the stress is $16.2 \mathrm{MPa}$, and, in the case of $m=3$ the stress is about 24.3 MPa. However, it is important to know that these are not reduced stresses but difference between two principal stress values obtained $\left(\sigma_{1}-\sigma_{2}\right)$. In order to clarify the flexible behavior of structures the applied inside overpressure was retracted to 0 bar several times. Up to a pressure of 7 bar the behavior of the structure was flexible, namely in the case of study of stress distribution test we have not found signs related to permanent deformation/strain. The failure (loss of operational functions) was occured at the value of 9.2 bar internal overpressure as you can seen in Fig. 16.

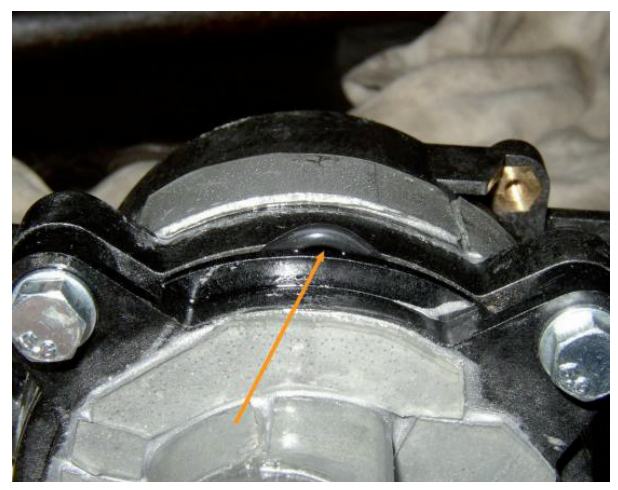

Fig. 16: The failure of the valve housing caused by the protrusion of the seal between the bolt connections (source: own photo).

The failure was occured when at the same time at two place which are perpendicular to each other - between the bolt connections - the seal bulged from the gasket nest (the liquid is ejected from the valve housing) and the pressure dropped, which means the loss of functionality.

\subsection{Results of the finite element analysis}

The numerical calculation has been made on the same pressure - 6 bar internal pressure - as the load case presented at the optical photostress analysis. As a result of the finite element analysis we get the nodal displacements in the nodes of the finite element mesh. From the nodal displacements using the material laws the post-processor can compute the specific elongations and the stress-components as well as the reduced von Mises stresses. In order to compare the results of the optical photostress analysis with the results of the finite element analysis we had to set up the difference between principal stresses $\left(\sigma_{1}-\sigma_{2}\right)$.
In order to ensure the right visibility in some cases we have made invisible the double-barreled part of the valve-housing. The following illustration shows the deformations related to the values for the internal pressure of 6 bar (Fig. 17.).
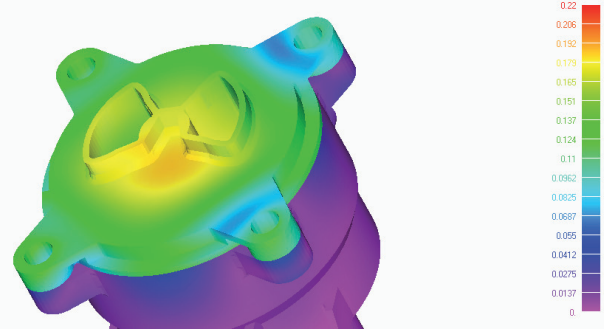

Fig. 17: The degree of deformation (values are given in millimetres) (source: own edition).

It is important to note that order to simplify the calculation the screws are not modeled in the assembly only given as a load to the clamping force exerted by. Consequently the displacements from bolt elongations bolts do not affect the result. The following figure shows the deformation as a result, the double-barrelled housing was humpbacked. For better visibility we have increased the deformation by a factor of 30 (see Fig. 18).

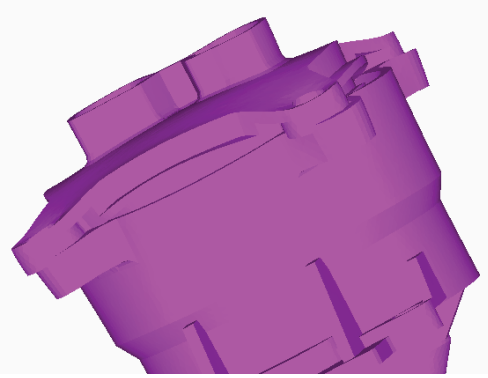

Fig. 18: As a result of the load the housing was humpbacked (source: own edition).

The internal pressure causes developing stress state can be observed caused the internal pressure with the following figures. In Fig. 19, it is easy to see that the case of the optical photoelastic investigation the areas to be examined were properly selected, since the maximum stresses appropriate places for the test layer has been glued (Fig. 19.).

The stress distribution on the investigated surface can be seen in Fig. 20.

The figures clearly show that the maximum stresses are formed in the immediate environment of the bolt connections but in this case it is not the 
subject of the investigation.

In order to ensure comparable with the results of optical phototstress method we have also created the difference between the principal stresses $\left(\sigma_{1}-\sigma_{2}\right)$ showing status (Fig. 21).

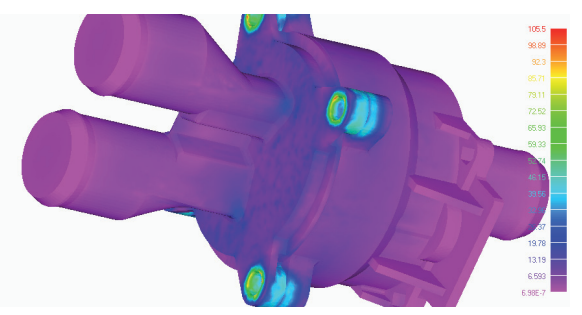

Fig. 19: The evolution of the reduced (von-Mises) stresses (values are given in $\mathrm{MPa}$ ), (source: own edition).

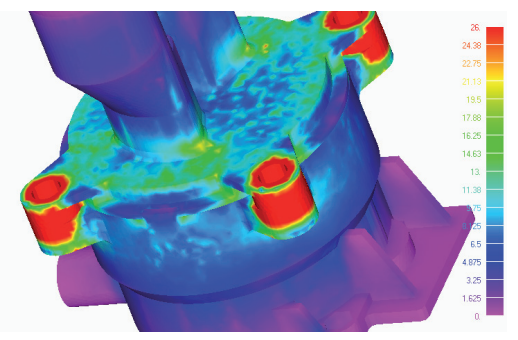

Fig. 20: Stress distribution on the investigated surface (values are given in $\mathrm{MPa}$ ), (source: own edition).

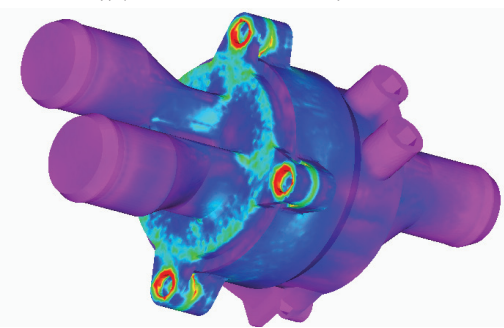

Fig. 21: Difference between the principal stresses $\left(\sigma_{1}-\sigma_{2}\right)$ on the complete assembled model (values are given in $\mathrm{MPa}$ ), (source: own edition).

The following figure magnified shows the same by focusing on the test area (Fig. 22).

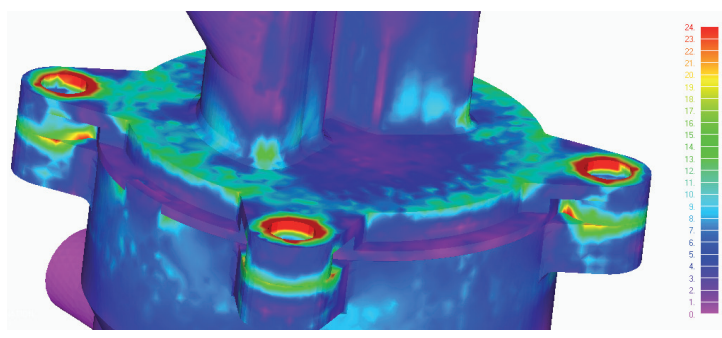

Fig. 22: Difference between the principal stresses $\left(\sigma_{1}-\sigma_{2}\right)$ on the investigated surface (values are given in MPa), (source: own edition).
The growing orientation of the stress can be observed very well. Humpbacked deformation leading to malfunction the structure shown in figure below. For better visibility the nature of the deformation the degree of deformation was increased 40-fold (Fig. 23).
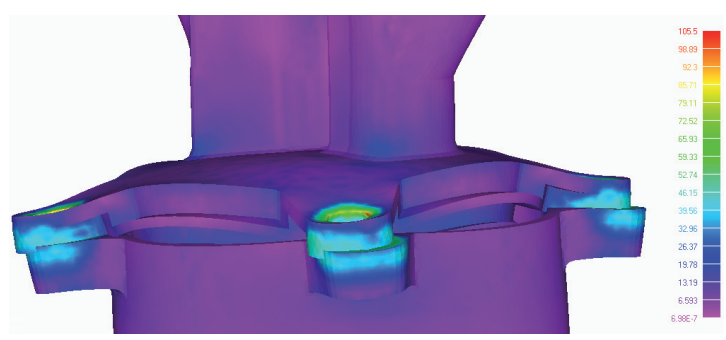

Fig. 23: Humpbacked deformation leading to malfunction (the degree of deformation was increased 40-fold.), (source: own edition).

\section{Analysis}

In this section will be comparing the results obtained by the optical photoelastic method carried out on the real structure and results of the numerical simulation. Both case the investigation was made by the same boundary conditions and by the same load cases (6 bar internal pressure). The left side of Fig. 24 can be seen (observed across polarizing filters) 6 bar load induced isochromatics (color bars) by the photo stress test. Directly next to the figure in the middle part drawn on the basis of the color bands and are assigned fringe pattern distribution can be observed.

Right-hand edge of the image can be seen from the results of the finite element analyis - after post processing - the distribution of the principal stresses $\left(\sigma_{1}-\sigma_{2}\right)$. Also in this figure by drawn the corresponding stress values each fringe pattern. The figure clearly shows that the two different procedure give a very good approximation, the same result. From this it is also one concludes that in the finite element analysis of loads and boundary conditions was taken correctly.

Fig. 25 displayed on the left-hand section of the location, rate and the nature of the causing failure - malfunction - humpbacked deformation on real model while on the other side of the image you can see the deformations - for that workload - in the computer simulation. On the basis of the figure it may be stated that the computer simulation results are almost identical. 

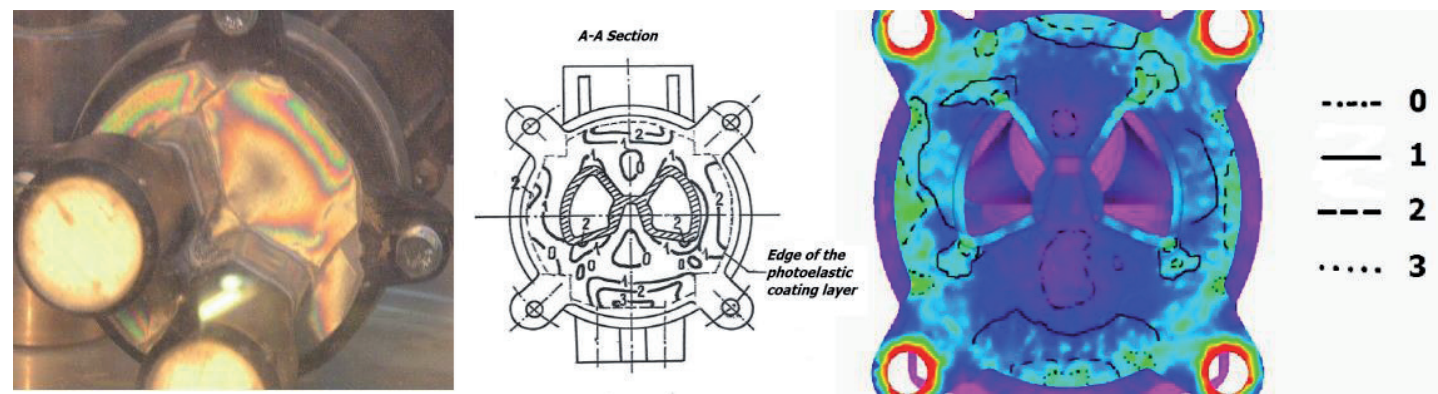

Fig. 24: The result of coating layered photstress method and numerical analysis (in case of $m=1, \sigma_{1}-\sigma_{2}=8.1 \mathrm{MPa}$ ); (source: own compilation).
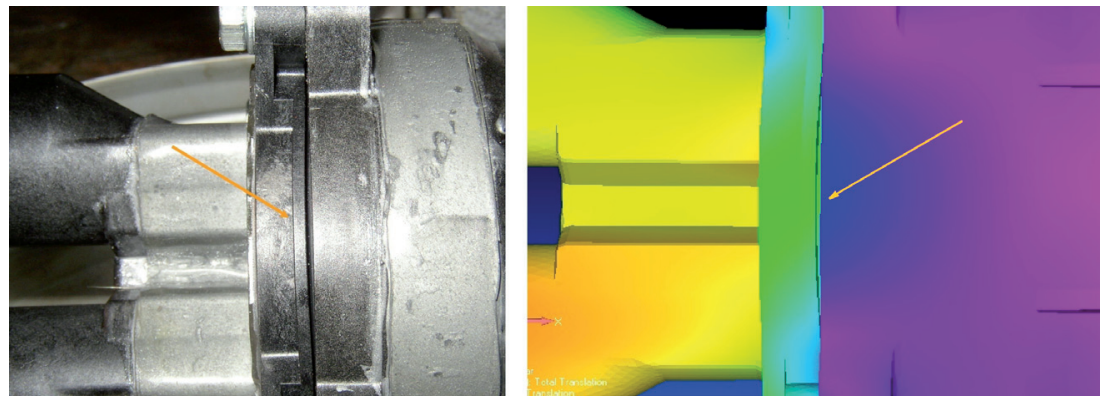

Fig. 25: A Humpbacked deformation leading to malfunction on real models and on the numerical model, (source: own compilation).

\section{Discussion}

Considering the various testing methods it can be concluded that significant difference between them as regards deformations and as far as the stress distribution results are not detectable.

- In the finite element analysis of loads and boundary conditions were correctly, the obtained values correspond to the reality.

- The combined use of the coating layered photostress method and the finite element analysis suitable for validate the determined experimentally previously unknown material laws and material properties.

However it is important to note that although in many cases the numerical simulation we can get more accurate results - assuming the exact knowledge of the loads and boundary conditions - in some cases, the results did not necessarily sufficient. This is the case for example the cause to malfunction by humpbacked deformation examined valve-housings in this paper, which loss due to leakage caused in this way lead to pressure drop. Although the degree of humpbacked deformation finite element analysis also showed exactly, that when he starts to "blow out" of the valve, we unfortunately can not answer. Therefore, it is important to note that for parts that require high level of se- curity in under any circumstances can not be left out of the experiments on real model. Our investigations also demonstrated that the best results are obtained when more than one test method is used in parallel.

\section{Acknowledgement}

This work is connected to the scientific program of the "Development of quality-oriented and harmonized R+D+l strategy and functional model at BME" project. This project is supported by the New Szechenyi Development Plan (Project ID: TÁMOP4.2.1/B-09/1/KMR-2010-0002). The authors are grateful to the support of Bólyai János Research fellowship of HAS (Hungarian Academy of Science). Authors are grateful for the support of Prof. Dr. Florian Heinitz, Director of Transport, and Spatial Planning Institute in Erfurt, Germany.

\section{References}

[1] Ficzere Péter, Borbás Lajos, Török Ádám, Resource analysis of rapid prototyping. Production Improvement. Trnava: Tripsoft, 2011. pp. 160-172.

[2] Mutnyánszky Á: Szilárdságtan. Múszaki könyvkiadó, Budapest, 1981. ISBN 9631035913.

[3] Borbás Lajos: Feszültségmérési eljárások. V. Fejezet pp.: 9922, Jármúfelépítmények vizsgálata. Egyetemi elektronikus 
tankönyv. BME Közlekedésmérnöki és Jármümérnöki Kar. Typotex kiadó, 2012., Kecskemét., ISBN 978-963-279-609-3

[4] Ficzere P., Borbás L.: Material law for numerical analysis of rapid prototype products 9th Youth Symposium on Experimental Solid Mechanics. Trieste, Italy, 2010.07.072010.07.10. pp. 9-12 (2010)

[5] Ficzere P., Borbás L.: Method to reduce the independent constants of orthotrop materials in rapid prototyping, 11th Youth Symposium on Experimental Solid Mechanics. Brasov, Románia, 2012.05.30-2012.06.02. Brasov: pp. 129-135.

[6] DuPont Zytel HTM Product Information: highe performance polyamid resin. Zytel HTN51G35HSLNC010. DUPONT (http. www.plastics.dupont.com)

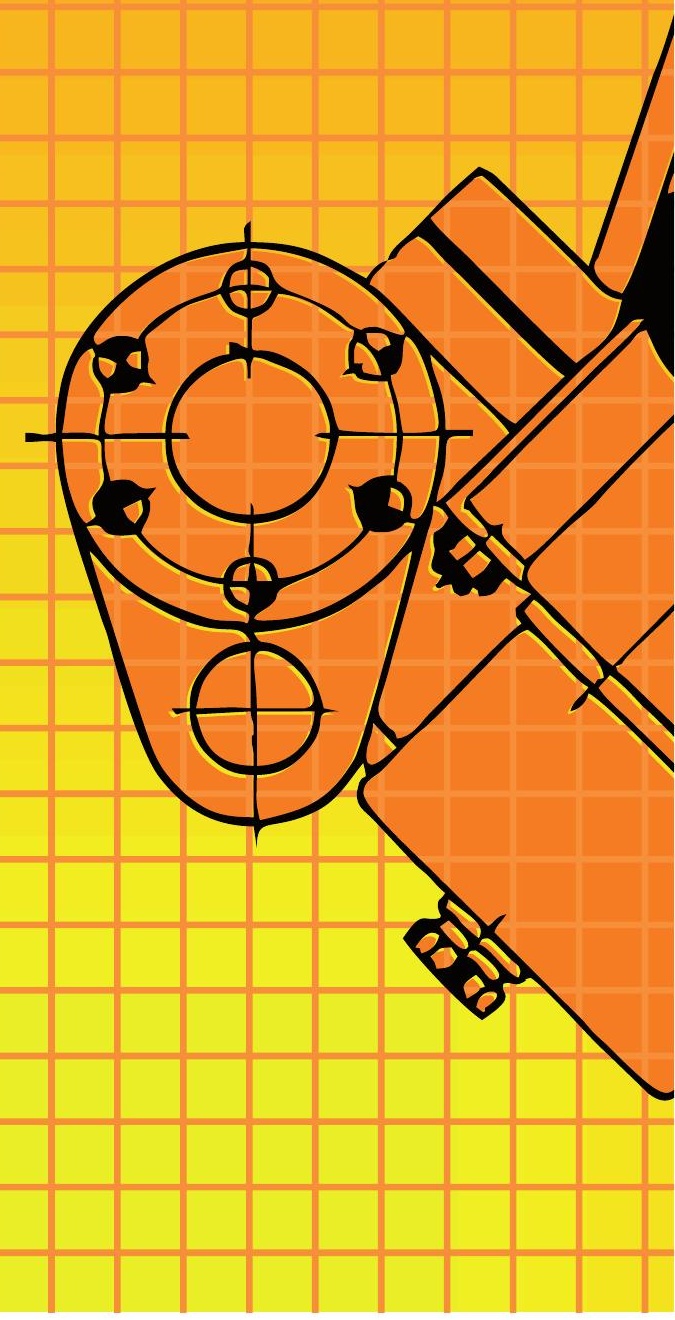




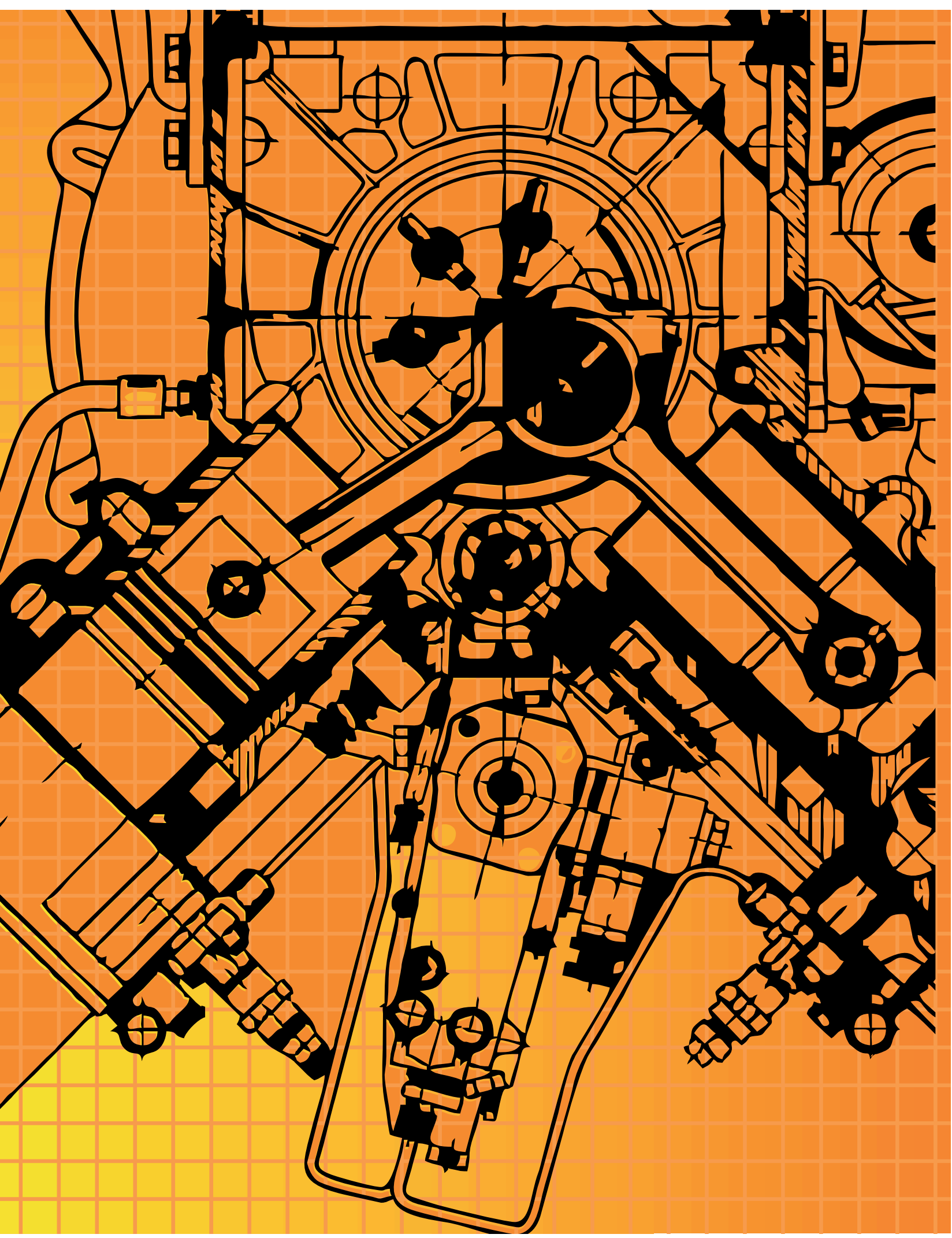

